\title{
The Study on the Insufficiency and Further Development of East Asian Foreign Exchange Reserve
}

\author{
Zhu Liping ${ }^{1, a^{*}}$ \\ ${ }^{1}$ Air Transport college, Shanghai University of Engineering Science, Shanghai, China \\ axwwzlp@163.com \\ ${ }^{*}$ Corresponding author
}

Keywords: East Asian Foreign Exchange Reserve, Insufficiency, Development

\begin{abstract}
Since 2003, after seven years of discussions and research, the East Asian Foreign Exchange Reserve Library officially began on March 24, 2010.Since its introduction, the East Asian Foreign Exchange Reserve has been highly anticipated. It will help maintaining regional economic and financial stability and provide a new platform for cooperation and exchanges for East Asian countries. This paper mainly analyzes and discusses the characteristics, existing shortcomings and future development of the East Asian foreign exchange reserve.
\end{abstract}

\section{Introduction}

The East Asian Foreign Exchange Reserve is called the Self-managed Reserve Pooling Arrangement (SRPA).It refers to ASEAN, China, Japan and South Korea each taking out a part of foreign exchange reserves to establish a common foreign exchange reserve fund. In non-crisis period, countries manage their own funds and concentrate on short-term financial assistance in the event of a crisis to help members solve the problem of liquidity difficulties.It originated from the bilateral currency exchange mechanism under the Chiang Mai Initiative(CMI) established after the Asian financial crisis, which is a multilateral exchange network established on the basis of it.On March 24, 2010, the East Asian Foreign Exchange Reserve Bank officially began. The establishment of the East Asian Foreign Exchange Reserve Bank will make better use of the abundant foreign exchange reserves in East Asia, maintain regional economic and financial stability, and provide a new platform for cooperation and exchanges for East Asian countries, which helping to promote the voice of Asian emerging economies in the world economic arena.

\section{Characteristics of the East Asian Foreign Exchange Reserve}

\subsection{Core principle}

The East Asian Foreign Exchange Reserve has been developed on the basis of CMI and has maintained two core principles of CMI.First, the East Asian Foreign Exchange Reserves is designed to deal with short-term liquidity problems in the region. Which means if the ASEAN 10+3 member states cause a balance of payments crisis due to insufficient temporary foreign exchange liquidity, foreign exchange funds will be provided through currency swap.Second, the East Asian foreign exchange reserve is positioned as a supplementary agreement of the IMF to compensate for the shortcomings and shortcomings of the existing international financing arrangements. The operation of the East Asian foreign exchange reserve is largely linked to the IMF-related provisions.

\subsection{Reserve size and investment ratio}

After many exchanges and consultations between ASEAN and China, Japan and South Korea, the final size and contribution ratio of the East Asian foreign exchange reserve pool were confirmed.The total size of the East Asian foreign exchange reserve is 120 billion US dollars, of which the ratio of capital contribution of China, Japan, South Korea and ASEAN member countries is 80:20.Specifically, China (including the Hong Kong Special Administrative Region) and Japan each 
invested US $\$ 38.4$ billion, accounting for $32 \%$ of the total size, and jointly became the largest "shareholder" of the foreign exchange reserve.; South Korea invested US\$19.2 billion, accounting for $16 \%$ of the total size of the reserve; the 10 ASEAN countries contributed US $\$ 24$ billion.In terms of the funding structure of each member country, countries use the promissory notes to fund the investment. In the future, they may consider using a unified global custodian on the basis of the promissory notes

\subsection{Loan conditions}

Each member of the East Asian Foreign Exchange Reserve has the right to use its own borrowing multiplier in exchange for a quantitative dollar in accordance with the requirements of the agreement in the difficult circumstances described in the agreement to resolve liquidity difficulties. The maximum amount each member country can borrow is the amount of each fund multiplied by its borrowing multiplier. The rules for determining the borrowing limit fully reflect the aid characteristics of the regional reserve pool. The borrowing multiplier is inversely proportional to the amount of capital contribution. The smaller the capital contribution, the larger the loan multiplier.

The ratio of borrowings from the East Asian Foreign Exchange Reserve to IMF is $20 \%$, which is consistent with the ratio in the bilateral currency swap arrangement.At the same time, all member states agreed to further increase the proportion of the East Asian Foreign Exchange Reserves monitoring mechanism after it has been effectively implemented to ensure that member states can withstand the crisis and uncertain risks.

\subsection{Management method}

In the non-crisis period, each country manages its own capital. In the event of a financial crisis, countries will jointly manage the crisis, and the reserve will provide loans to members with financial liquidity difficulties.

\subsection{Decision mechanism}

The decision-making mechanism of the East Asian Foreign Exchange Reserve Bank is mainly resolved by consensus or by voting. When the major issues related to the development of the East Asian foreign exchange reserve need to be resolved, the decision-making mechanism adopted by the reserve is determined by the ASEAN+3 member states; When it comes to the settlement of the borrowing problem, the decision-making mechanism is to vote between the member states, and the majority vote passed.

\subsection{Supervision mechanism}

In terms of the establishment of the supervisory authority, the member states agreed to establish an independent regional supervision mechanism as soon as possible to monitor and analyze the regional economic situation and support the decision of the regional reserve.As a transitional arrangement, Member States agreed to establish an expert advisory committee and provide organizational support for the oversight function of the regional reserve pool, using the existing mechanisms of the Asian Development Bank (ADB) and the ASEAN Secretariat.

\section{Insufficiency of East Asian foreign exchange reserves}

\subsection{East Asian foreign exchange reserve has limited loan capacity}

The East Asian Foreign Exchange Reserve has limited loan capacity for two main reasons: First, the total size of the reserve and the proportion of capital contribution from countries are low; second, the proportion of loans linked to IMF is too high.The ratio of the East Asian Foreign Exchange Reserve to the IMF is $80 \%$, although the member states indicated that this ratio will be further reduced when the monitoring mechanism of the reserve pool is effectively operated, at present, $80 \%$ is too large, which has certain restrictions on the borrowing of member countries to apply for the 
reserve.Although linking the stockpile's borrowings to the IMF can effectively prevent the moral hazard of the borrower's misuse of the stockpile borrowing, and also helps the borrowing country to actively adjust its policy structure, but its drawbacks are also obvious.

\subsection{Loose management of the East Asian foreign exchange reserve}

According to the agreement, during the non-crisis period, the East Asian Foreign Exchange Reserve Bank will manage the foreign exchange reserves of the central banks themselves and wait for the financial crisis to be concentrated for financial assistance. This is very different from the International Monetary Fund, which organizes the funds of each member into one account and can allocate it directly when needed.This loose management of the East Asian Reserve Library has greatly affected the operational efficiency of the regional rescue mechanism.Moreover, the management of the reserve pool at the time of the crisis and the responsibility and decision of the use of the reserve are still unresolved issues.

\subsection{Inefficient decision-making mechanism}

The East Asian Foreign Exchange Reserve uses a consensus principle for major issues, which is quite different from IMF's major issue requiring $85 \%$ of voting rights. The principle of consensus can better reflect the cooperation model of equality, mutual benefit, seeking common ground while reserving differences and common development in the reserve pool, avoiding the phenomenon of one country's independence, and more conducive to promoting the enthusiasm of all countries, especially small countries, to participate in cooperation.However, there are inevitably problems of long negotiation time, high coordination costs and low efficiency.

\subsection{No independent and efficient monitoring mechanism has been formed}

An independent monitoring agency is the key to ensuring the effective operation of the regional foreign exchange reserve.At present, member states have reached an initial consensus on establishing an independent monitoring body as soon as possible, which is the strength of the Asian Development Bank and the ASEAN Secretariat will be needed during the transition period.The existing monitoring mechanism under the 10+3 framework is mainly the "Economic Prediction and Policy Dialogue" (ERPD), and member states use ERPD as a starting point and foundation to strengthen cooperation in regional testing in East Asia. At present, countries are constantly improving ERPD, such as increasing the frequency of dialogue and developing standardized models that provide necessary data and information.However, ERPD still has obvious defects. It relies solely on the information provided by member states for monitoring.It does not actively and independently conduct detailed investigations of members, which greatly limits the effectiveness of monitoring.

\section{Further development of the East Asian Foreign Exchange Reserve Bank}

\subsection{Improve the operability of the East Asian foreign exchange reserve crisis rescue mechanism}

To be an important way for regional countries to cope with the crisis, the East Asian foreign exchange reserve must have different advantages from IMF. This is also the original intention of Asian currency cooperation.In 1997, the Asian financial crisis made East Asian countries quite dissatisfied with IMF's loan conditions, negotiation time, and rescue programs during the crisis. Therefore, it hopes to establish a more timely and effective regional crisis rescue mechanism. At present, the East Asian foreign exchange reserve pool is not a substitute for the role of IMF, nor does it have the ability to completely decouple from IMF, but it can be promoted in two aspects:

(1)Expand the size of the reserve.Expanding the size of the reserve is mainly based on two considerations: 1) according to the current loan arrangement, the proportion of independent loans in the reserve pool is only $20 \%$, and the financial support available to member states is very limited. Expanding the size of the reserve pool will undoubtedly become the only way to improve the loan 
capacity.2) from the perspective of regional optimal reserve scale, the scale of the East Asian foreign exchange reserve pool of 120 billion US dollars is obviously insufficient. Some analysts believe that the current reserve size only accounts for about $10 \%$ of the regional optimal reserve size. Therefore, it is also feasible to further expand the size of the reserve.

(2)According to the current agreement, the East Asian Foreign Exchange Reserve adopts a decentralized management approach. During the non-crisis period, central banks manage their own foreign exchange reserves and wait for the financial crisis to be concentrated for financial assistance. When crisis suddenly broke out, how the reserve pool realized the effective allocation of reserve funds, there are still many technical problems. There is no doubt that centralized management of reserves and the establishment of a unified account are more effective, but this depends mainly on whether Member States have a stronger willingness to cooperate.

\subsection{Expand the investment function of the foreign exchange reserve}

At present, the function of the foreign exchange reserve is mainly targeted at crisis relief, with the main goal of solving the short-term liquidity problems of member states. However, the outbreak of the crisis is an extraordinary event. In non-crisis period, the East Asian foreign exchange reserve pool, as a new platform for Asian currency cooperation, needs to expand other functions.Utilizing the cooperation platform of the East Asian Foreign Exchange Reserve Bank to effectively manage the large-scale reserve assets of various countries, it can not only diversify asset risks, but also promote the construction of regional financial markets, especially Asian bond markets.Expanding the investment function of the reserve pool, in terms of specific operations, it is necessary to establish a cooperative investment fund and establish a joint management reserve organization responsible for investment decision-making and daily operations, which is also beneficial to strengthen the organization of Asian currency cooperation.

\subsection{Strengthen regional information sharing and monitoring mechanisms}

Regional information sharing and monitoring mechanisms are important for risk assessment and crisis prevention. In order to strengthen supervision, ASEAN 10+3 has decided to set up a permanent secretariat in Singapore (ASEAN+3 Macroeconomic Research Office: AMRO) and has established personnel arrangements in May 2011.AMRO's goal is to "become an independent, Asian-focused macroeconomic monitoring and crisis relief mechanism" to promote regional economic monitoring and analysis and support the implementation of the Chiang Mai Initiative Multilateralization Agreement. The establishment of this institution will contribute to the deepening development of East Asian monetary cooperation in monitoring and monitoring mechanisms.

\section{References}

[1] YuYongding, He Fan and Li Jing, Asian Financial Cooperation: Background, Latest Developments and Prospects, International financial research, vol.2, pp. 6-12, 2002.

[2] He Fan, Zhang Bin and Zhang Ming, Evaluation and Reform Suggestions for the Chiang Mai Agreement, International financial research, vol.7, pp. 16-22, 2005.

[3] Zheng Haiqing, Regional response to the financial crisis:East Asian Foreign Exchange Reserve, World economic research, vol.12, pp. 78-86, 2009.

[4] Zheng Haiqing, The Theory and Empirical Analysis of the Income of the East Asian Foreign Exchange Reserve Bank, International financial research, vol.5, pp. 22-29, 2008.

[5] Zheng Liansheng, East Asian Foreign Exchange Reserve: How big can solve, World knowledge, vol.11, pp. 31-33, 2009. 